\title{
CONCEPÇÕES E PRÁTICAS DOS PROFISSIONAIS DE SAÚDE ACERCA DA VIOLÊNCIA INTRAFAMILIAR CONTRA CRIANÇAS E ADOLESCENTES
}

\author{
CONCEPCTIONS AND PRACTICES OF HEALTHCARE PROFESSIONALS REGARDING INTRAFAMILY \\ VIOLENCE AGAINST CHILDREN AND ADOLESCENTS
}

\section{CONCEPCIONES Y PRÁCTICAS DE LOS PROFESIONALES DE LA SALUD ACERCA DE LA VIOLENCIA INTRAFAMILIAR CONTRA NIÑOS Y ADOLESCENTES}

\author{
Dayse Kalyne Gomes da Costa ${ }^{1}$ \\ Lucas Pereira Reichert ${ }^{2}$ \\ Jael Rúbia Figueiredo de Sá França ${ }^{3}$ \\ Neusa Collet ${ }^{4}$ \\ Altamira Pereira da Silva Reichert ${ }^{5}$
}

Resumo Estudo qualitativo com profissionais da Estratégia Saúde da Família, a fim de investigar suas concepções e práticas acerca da violência intrafamiliar contra crianças e adolescentes. A coleta de dados foi realizada no período de abril a julho de 2014, por meio de entrevista semiestruturada, realizada em Unidades Integradas de Saúde da Família em João Pessoa, Paraíba. A análise temática evidenciou que profissionais de saúde mostram-se inseguros e despreparados para lidar com a violência intrafamiliar contra crianças e adolescentes, originando dificuldades em identificar os maus-tratos, realizar a denúncia e acompanhar as vítimas. Destaca-se a importância do apoio da gestão em saúde para a proteção dos profissionais que lidam com casos de violência e sua capacitação, a fim de viabilizar a identificação precoce, a notificação dos casos e o efetivo acompanhamento às vítimas e seus familiares. Palavras-chave violência doméstica; saúde da criança; adolescente; atenção primária à saúde; profissional de saúde.
Abstract A qualitative study with Family Health Strategy professionals to investigate their views and practices concerning domestic violence against children and adolescents. Data were collected between April and July 2014 using semi-structured interviews carried out at Integrated Family Health Units in João Pessoa, state of Paraíba, Brazil. The thematic analysis showed that health professionals are insecure and unprepared to deal with domestic violence against children and adolescents, a fact that causes difficulties in identifying maltreatment, making the complaint, and monitoring the victims. It highlights the importance of support from health management to protect professionals who deal with cases of violence and their training in order to facilitate the early identification and reporting of cases and effective monitoring for victims and their families.

Keywords domestic violence; child health; adolescents; primary health care; health professional. 


\section{Introdução}

A Organização Mundial da Saúde define a violência como sendo o uso intencional de força física ou poder, por meio de ameaças ou de forma concreta, infligida a si mesma, a outra pessoa, a um grupo ou à comunidade, provocando ou possibilitando o aparecimento de lesão, morte, dano psicológico, deficiência no desenvolvimento ou privações (Aragão et al., 2013). $\mathrm{O}$ artigo $5^{\circ}$ do Estatuto da Criança e do Adolescente (ECA) estabelece que

Nenhuma criança ou adolescente será objeto de qualquer forma de negligência, discriminação, exploração, violência, crueldade e opressão, punindo na forma da lei qualquer atentado, por ação ou omissão, aos seus direitos fundamentais (Brasil, 2008, p. 14).

De acordo com o Mapa da Violência, de todos os atendimentos computados no ano de 2011 pelo Sistema de Informação de Agravos de Notificação, 40\% corresponderam a casos de violências contra crianças e adolescentes. Foram registradas 39.281 notificações de violência na faixa de menor de um a 19 anos idade, sendo evidenciado que as agressões ocorreram, preponderantemente, na residência das vítimas (Waiselfisz, 2012). Portanto, a violência passou a ser considerada um importante problema de saúde pública (Brasil, 2010).

Entretanto, esses dados não representam a real situação de violência contra menores, pois grande parte dos casos permanece invisível diante dos profissionais e do sistema de saúde, em consequência de deficiências na identificação e denúncia dos maus-tratos (Nunes, Sarti e Ohara, 2009).

A violência intrafamiliar contra crianças ou adolescentes corresponde a qualquer ação ou omissão que prejudique o bem-estar, a integridade física ou psicológica, ou a liberdade e o direito ao pleno desenvolvimento dessa população (Angelo et al., 2013) no âmbito da família. Pode ser cometida dentro ou fora de casa e é perpetrada por algum membro da família, incluindo pessoas que passam a assumir função parental, ainda que sem laços de consanguinidade, e em relação de poder à outra (Moreira e Sousa, 2012) com finalidade de dominação, exploração e opressão do adulto sobre o menor (Silva et al., 2009). A violência intrafamiliar, em geral, atinge mais as crianças do que os adolescentes, em função de sua maior fragilidade física e emocional (Brasil, 2010), e inclui as mais variadas formas de violência interpessoal (violência ou agressão física, violência ou abuso sexual, violência ou abuso psicológico, negligência, abandono e outras) (Brasil, 2012; Rocha e Moraes, 2011).

Ao considerar que a Unidade de Saúde da Família (USF) está inserida no mesmo território em que a população assistida reside, os profissionais que atuam nesse serviço ocupam posição estratégica na prevenção, identificação 
de indivíduos e grupos de risco para maus-tratos e no desenvolvimento de intervenções adequadas à situação de violência (Souza et al., 2009).

Entretanto, os profissionais que atuam na Estratégia Saúde da Família (ESF) não se encontram preparados para lidar com a violência, uma vez que se deparam com casos e não conseguem identificá-los ou não sabem lidar com a situação, contribuindo para o seguimento da violência, invisibilidade da ocorrência e, consequentemente, prolongamento do sofrimento das vítimas (Cocco et al., 2010).

Diante disso, emergiram os seguintes questionamentos: Qual a concepção dos profissionais de saúde da ESF acerca da legislação de proteção às crianças e adolescentes vítimas de violência intrafamiliar? No cotidiano, durante a consulta, esses profissionais atendem crianças e adolescentes vítimas de violência intrafamiliar? Quais as suas condutas diante da violência? Este estudo objetivou conhecer as concepções e práticas dos profissionais da ESF acerca da violência intrafamiliar contra crianças e adolescentes.

A realização de pesquisas que envolvam as concepções e práticas de profissionais de saúde acerca da violência contra crianças e adolescentes é de grande relevância, pois possibilita compreender o processo de trabalho desses profissionais diante de um fenômeno tão impactante como esse e permite refletir sobre maneiras para buscar seu aprimoramento.

\section{Método}

Delineou-se um estudo de caráter exploratório-descritivo, 6 com abordagem qualitativa, baseado no depoimento de profissionais que atuam na ESF quanto a suas concepções e práticas acerca da violência intrafamiliar contra crianças e adolescentes.

A pesquisa de campo foi realizada em USFs pertencentes a um dos cinco distritos sanitários de uma cidade da Paraíba. Tal escolha deveu-se ao fato de o referido distrito estar localizado na área de abrangência da Universidade Federal da Paraíba, o que favorece o acesso ao campo de pesquisa, por este constituir-se como cenário de prática dos cursos de graduação dessa instituição. Foram priorizadas as unidades integradas de saúde devido à facilidade de acesso aos profissionais, tendo em vista que lá trabalham quatro equipes de saúde da família em um único espaço físico.

Os participantes da pesquisa foram 15 profissionais de nível superior que atuam em USF, entre eles enfermeiros, médicos e dentistas. A escolha desses profissionais se deu por eles terem contato com crianças e adolescentes, em atendimento individual ou coletivo, aumentando a possibilidade de identificação dos casos de violência intrafamiliar infanto-juvenil. Foram eleitos a partir dos seguintes critérios: ser enfermeiro, médico e dentista que atendesse a 
criança ou adolescente cadastrado na área de abrangência das USFs, atuasse nas USFs por um período mínimo de um ano e estivessem em atividade profissional durante o período de coleta de dados. E, como critério de exclusão: enfermeiros, médicos e odontólogos que estivessem ausentes do trabalho por motivo de férias ou licença no período da coleta dos dados.

A coleta de dados empíricos foi realizada no período de abril a julho de 2014 por meio de entrevista semiestruturada, que foi gravada em mídia digital, após anuência dos entrevistados, e transcrita na íntegra para posterior análise. $\mathrm{O}$ instrumento para coleta de dados baseou-se em um roteiro composto pelas seguintes questões norteadoras: Você pode relatar sinais de violência intrafamiliar em crianças e adolescentes? Já aconteceu de você atender alguma criança ou adolescente vítima de violência intrafamiliar? Você conhece a ficha de notificação compulsória para os casos de violência? Em que casos ela é utilizada?

As entrevistas foram agendadas de acordo com a conveniência dos participantes, com exceção dos profissionais que preferiram realizá-la já no primeiro contato. A maioria dos profissionais de saúde optou pela entrevista nos dias de reunião de equipe, pela maior disponibilidade naquele momento e para não interferir no atendimento à comunidade.

Para manter o anonimato dos participantes do estudo, os depoimentos oriundos das entrevistas foram identificados com a letra inicial correspondente à categoria profissional à qual pertencem, seguida do número da sequência da entrevista.

No que se refere à interpretação dos dados, seguiram-se os passos da análise categorial de conteúdo a partir das seguintes etapas: pré-análise; exploração do material; tratamento e interpretação dos resultados. A pré-análise ocorre após transcrição dos áudios gravados, em que os dados são organizados para dispô-los em uma determinada ordem, de forma a realizar uma classificação inicial. Em seguida, na fase de exploração do material, traçou-se o mapa horizontal do material e foram realizadas sucessivas leituras dos textos, buscando-se uma relação com os objetivos do estudo, a fim de constituir as estruturas de relevância. Posteriormente, na fase de tratamento e interpretação dos resultados, realizou-se o reagrupamento dos temas mais relevantes para a análise final e consequente construção das categorias temáticas (Bardin, 2011).

Atendendo à resolução n. 466/2012 do Ministério da Saúde, que regulamenta a realização de pesquisas envolvendo seres humanos, o projeto desta pesquisa foi aprovado pelo Comitê de Ética em Pesquisa do Centro de Ciências da Saúde da Universidade Federal da Paraíba, cujo parecer foi favorável (protocolo n. 0620/13). Para todos os sujeitos participantes foi apresentado o termo de consentimento livre e esclarecido, o qual continha o objetivo da pesquisa e sua forma de realização, para que pudessem acenar com sua anuência, caso quisessem participar dessa investigação, bem como desistir de 
sua participação a qualquer momento da pesquisa, garantindo-lhes o anonimato e sigilo de informações.

\section{Resultados e discussão}

Dos 15 profissionais participantes da pesquisa, nove eram enfermeiros, quatro dentistas e dois médicos. Destes, dois eram do sexo masculino. O tempo de formação profissional variou de 29 a 40 anos entre os médicos, de quatro a 20 anos entre os dentistas e de dois a 30 anos entre os enfermeiros. Já o tempo de atuação na USF variou de um a 13 anos entre as três categorias profissionais.

A partir da análise dos dados, foram construídas duas categorias temáticas: Identificação da violência intrafamiliar contra crianças e adolescentes; e Conduta profissional diante da violência intrafamiliar contra crianças e adolescentes.

\section{Identificação da violência intrafamiliar contra crianças e adolescentes}

O profissional de saúde que atua na ESF está em permanente contato com crianças, adolescentes e familiares no desenvolvimento de suas atividades, seja na unidade de saúde, seja no domicílio. Esses espaços são privilegiados para a identificação de sinais e sintomas de maus-tratos, além de propiciarem a promoção dos cuidados necessários para assistir às vítimas e às famílias para prevenção e superação da violência (Brasil, 2010).

Ao serem questionados quanto aos sinais e sintomas que podem ser identificados nas crianças ou adolescentes vítimas de violência intrafamiliar, os profissionais relataram:

Uma mãe que tem bem três filhos, quatro filhos, e não cuida. Ela chega aqui na unidade, é um horror de sujeira e até foi encontrado larva no canal vaginal da criança. Quer dizer, isso não deixa de ser violência, né, maus-tratos (E 1).

Eu percebo, assim, as crianças mais agitadas, não aceitam o toque da gente, do examinador (...) com medo de todo mundo e, algumas vezes, assim, algumas marcas (...) a própria criança fica muito arredia e parece timidez, mas na verdade é a defesa que ela encontra de se esconder (E 2).

Aqui a gente vê muito, muito violento (...) tanto nas palavras, quanto também em gestos, em querer bater. E isso é questão psíquica. Aí tem a questão do corpo, né, que pode aparecer uns hematomas, umas marcas de queda não sei de onde (...) um dentinho quebrado, inchadinho, um roxinho aqui e acolá. Às vezes, a gente pega também beliscão, arranhão (E 10). 
A partir dos relatos pode-se perceber maior referência às manifestações físicas da violência, nos quais os profissionais mostram-se mais atentos aos sinais explícitos das agressões. Uma situação que merece destaque diz respeito ao fato de que as violências sexual e psicológica não foram mencionadas por nenhum dos entrevistados, apesar de sua gravidade para a saúde física e mental de crianças e adolescentes.

Estudo realizado nos Estados Unidos com 1.025 crianças entre dois e 17 anos mostra que, após análise de regressão, a violência psicológica mostrou-se a única significante e mais danosa aos jovens, sendo a que deixa mais sequelas permanentes. Tal estudo também afirma que crianças e adolescentes que sofreram tal forma de violência são mais suscetíveis a serem vitimadas novamente, inclusive, com eles próprios sendo protagonistas da violência (Cuevas et al., 2010). Portanto, os profissionais devem não apenas se preocupar com os danos psicológicos causados, mas também com os riscos de ocorrência de novos episódios de violência.

A falta de conhecimento do profissional de saúde sobre os sinais da violência constitui uma barreira para a identificação dos maus-tratos e a manutenção do ciclo de violência contra crianças e adolescentes (Cocco, Silva e Jahn, 2010). O despreparo em identificar, notificar e acompanhar os casos de violência intrafamiliar infanto-juvenil torna invisível grande parte das ocorrências (Cocco et al., 2010).

Um aspecto fundamental para a atuação do profissional de saúde na prevenção da violência e promoção da cultura da paz é o vínculo que ele estabelece com a comunidade sob seus cuidados. Nos casos em que não há uma boa relação de vínculo, a violência acontece no seio da família e os profissionais não identificam, sabendo do ocorrido só por meio de outras pessoas ou mesmo pela mídia, conforme mostra a fala a seguir:

A gente teve uma criança que veio, mas quando ela veio, foi até ruim da gente abordar, porque quando a mãe trouxe, já tinha divulgado na mídia (...) então a vizinhança todinha já sabia. Aí foi difícil de a gente abordar, ela tinha ido para delegacia e tudo, que foi um caso de estupro de um menino de 12 anos (E 8).

A formação de vínculos, aliada à criação de laços de compromisso e corresponsabilidade entre os profissionais de saúde e a comunidade, proporciona uma relação de confiança e respeito que promove um serviço de qualidade, como também o reconhecimento do profissional perante os usuários do serviço. Mas, para que o vínculo seja efetivo, a comunidade necessita reconhecer que a equipe de saúde tem a capacidade de resolver seus problemas. Essa concepção é eliminada no momento em que o usuário não recebe o atendimento desejado, em decorrência de um sistema que tem fragilidades em atender às suas necessidades (Teixeira et al., 2013). 
A violência cometida contra crianças e adolescentes no ambiente familiar não é um fenômeno recente e, na maioria das vezes, é justificada culturalmente como uma maneira de educar e corrigir um comportamento considerado inadequado (Rocha e Moraes, 2011), como expressam as seguintes falas:

Acho que ela tinha, em média, uns dois anos de idade (...) começou a ficar muito arredia e a mãe estava trazendo porque ela estava (...) sem comer, sem nem querer sair de casa, tinha medo, chorava quando pegava no colo (...) depois de muito tempo (...) começou a contar que ficava de castigo, que apanhava na palma da mão se contasse que ela não queria comer. A cuidadora queria, porque queria, que ela comesse à força (E 2).

Acho que ele tinha uns cinco ou seis anos. Aí ele não queria deixar eu realizar, né, o atendimento. Nesse momento os avós, inclusive, agrediram ele (sic) no momento do atendimento e ameaçaram, também, de quando saísse que ele iria ser agredido se não deixasse realizar os procedimentos $(\mathrm{O} 3)$.

A gente tá fazendo a consulta, aí aquela mãe que tem três, quatro, cinco filhos, que chega aquela escadinha sabe, grita pra cá e é palavrão pra lá e chega e puxa (E 10).

É possível verificar que o núcleo familiar, em vez de cumprir com seu papel de protetor da criança e do adolescente, abstém-se das suas responsabilidades ou torna-se o provedor de atos violentos, que são geradores de consequências perturbadoras para o desenvolvimento emocional das vítimas, comprometendo-lhes o bem-estar e o desempenho psicossocial.

Nesse contexto, alguns dos entrevistados demonstraram visualizar a negligência não como uma forma de violência, mas, sim, como um descuido do responsável pela criança:

O que a gente, às vezes, observa é mais a questão assim da falta de cuidado, não é nem violência. É assim o descuido, não trazer para a puericultura, entendeu? De ficar prorrogando uma doença (E 8).

Não, graças a Deus, aqui na unidade a gente não pegou nenhum caso de agressão. Já teve casos, assim, vamos dizer, maus cuidados, a gente chegar e paciente estar sujo, sem trocar fralda, mas de agressão não (E 6).

A negligência é um tipo de violência contra crianças e adolescentes que é caracterizada pela privação de algo que é necessário ao adequado desenvolvimento físico, mental e social desses indivíduos. Nesse caso, as necessidades básicas dos menores não são atendidas e os pais ou cuidadores fracassam em 
promover alimentação, higiene, vestimenta, moradia, apoio emocional e cuidados de saúde (Brasil, 2012; Thomazine, Oliveira e Vieira, 2009).

Esse tipo de violência pode ocorrer também por falta de orientação dos profissionais aos pais ou cuidadores quanto aos cuidados necessários para o bem-estar da criança, tornando-se uma responsabilidade do profissional de saúde identificá-la e preveni-la.

\section{Conduta profissional diante da violência intrafamiliar contra crianças e adolescentes}

Os profissionais de saúde têm papel de destaque no atendimento às crianças e adolescentes vítimas de violência, agindo desde a identificação de sinais físicos e comportamentais ao tratamento de agravos, notificação e acompanhamento do caso, além do desenvolvimento de ações educativas junto às famílias e à comunidade (Silva, Ferriani e Silva, 2011). Entretanto, os depoimentos a seguir revelam certa dificuldade dos participantes do estudo em lidar com a violência:

É uma criança que a mãe e o pai morreram e a avó quem cuidava dele. Ele é bem agressivo. A avó brigava com ele, no início ele não entrava na sala, ele gritava. Ela vinha, puxava ele ( $(i c)$, botava uma cadeira, você vai fazer senão eu vou fazer num sei o que lá. Aí ficava segurando os cabelos do menino. Quando ela estava muito estressada, a gente via a hora [que ia] acontecer alguma coisa. Tanto que eu saí da sala, não fiquei nem na sala em um momento lá (...) não tinha como, você fica todo paramentado, você não tem como defender muito, né, o menino. A defesa da gente era não atender $(\mathrm{O} 2)$.

Na primeira vez, eu fiquei com medo (...) na segunda vez, eu disse assim: olhe, eu não quero que você bata nele, nem segure, nem faça nada aqui, porque eu não vou deixar. Se você for fazer, vou pedir para você sair (O 3).

É possível identificar que é mais fácil perceber a violência dentro do serviço de saúde, não sendo, porém, mais simples intervir, levando o profissional, em alguns casos, a abrir mão de sua autonomia e autoridade dentro do serviço, tornando-se complacente com a situação.

Ao analisar o conjunto de fatores envolvidos na prática do cuidado e da prevenção à violência contra crianças e adolescentes na ESF, constata-se a ausência de suporte institucional aos profissionais que, sem o apoio do serviço, acabam tomados por preconceitos e medos, utilizando estratégias que os resguardem (Luna, Ferreira e Vieira, 2010).

Alguns profissionais receiam se envolver em casos de violência por temerem as demandas judiciais e apresentam medo de sofrerem represálias 
por parte dos agressores (Saraiva et al., 2012). Essa situação pode ser confirmada a partir dos seguintes depoimentos:

Na primeira vez, eu fiquei com medo de dizer assim: não, não faça isso, não bata, essas coisas (O 3).

Quem denunciou foi a vizinha e essa vizinha saiu da casa porque ele ameaçou (...) é uma coisa muito difícil de entrar em contato com esse povo (...) porque eles não aceitam a intervenção (...) a gente arrisca muito a nossa vida. (...) a equipe, a gente realmente não se envolve, porque a gente tem medo da ação da comunidade, entendeu? (...) pode vir ameaça pra gente (E 9).

No decorrer das entrevistas, os profissionais trouxeram constantemente o temor de se envolverem nos casos de violência, por trabalharem na área onde, muitas vezes, a vítima e o agressor residem. Diante do receio de se tornarem novas vítimas, eles preferem silenciar diante da situação ou repassar a responsabilidade para outro profissional.

Diversos estudos apontam a existência do temor dos profissionais da atenção primária de se envolverem diretamente nos casos de violência contra crianças e adolescentes (Algeri e Souza, 2006; Nunes, Sarti e Ohara, 2009; Aragão et al., 2013), optando por silenciarem diante do problema, o que vem a corroborar aos achados deste estudo. Essa situação é compreendida como um fator comprometedor diante das relações instituídas entre os profissionais e a comunidade, e geradora da subnotificação dos casos identificados (Aragão et al., 2013).

Outra dificuldade identificada no manejo desses casos diz respeito à sensibilidade necessária ao profissional para lidar com prováveis vítimas desse tipo de violência. O saber ouvir além das palavras, observar atentamente as expressões e gestos manifestados pelas crianças ou adolescentes, perceber no silêncio e na sutileza as marcas da violência:

A violência, principalmente das crianças, é muito sutil, muito escondidinha, muito guardada, pouco é deixado rastro (E 2).

Geralmente ele nega que foi agredido, que foi por alguém da família (E 6).

Essas falas evidenciam a ocorrência de obstáculos no cuidado pelos profissionais da ESF às crianças e adolescentes vítimas de violência intrafamiliar, principalmente no que diz respeito à identificação e notificação dos maus-tratos. Essa dificuldade torna invisível grande parte dos casos, contribuindo para a perpetuação da violência.

Diante de situações como essa, o profissional não precisa absorver toda a tarefa de solução do problema, mas acionar o conselho tutelar, considerado 
fundamental no acolhimento dos casos e encaminhamento de vítimas e suas famílias, garantindo-lhes proteção e apoio (Cocco et al., 2010). Alguns participantes da pesquisa mencionaram essa instituição como um aliado na assistência às vítimas de violência e seus familiares:

A gente tem um caminho direto com o conselho tutelar, que ajuda bastante (...) funciona até certo ponto, pelo menos o instrumento a gente tem, agora, como é feito é mais complicado (E 2).

A gente faz visita, então, quando vê que é uma pessoa que tem um certo conhecimento, a gente tenta orientar, mas se não tiver (...) a gente encaminha para o conselho tutelar. Se a família vai ou não, aí a questão é de cada um (E 9).

Segundo a lei n. 13.010/2014 (menino Bernardo), é direito da criança não mais sofrer ameaças, humilhações ou tratamentos cruéis, sendo obrigação dos profissionais de saúde, ao tomarem conhecimento de tais agressões, notificar o caso para o conselho tutelar para que as medidas jurídicas cabíveis sejam tomadas (Brasil, 2014). Porém, as falas dos entrevistados revelam uma atitude de desresponsabilização de alguns profissionais, no momento em que apenas referenciam o caso para o conselho tutelar e não acompanham a família no processo, ausentando-se do dever ético-legal de notificá-los e acompanhá-los diante do caso de violência.

Os profissionais também utilizam os serviços dos agentes comunitários de saúde (ACS) para investigar e acompanhar os casos de violência contra crianças e adolescentes na sua área de atuação:

A gente comunica à equipe, ao ACS pra fazer uma investigação mais precisa, pra poder de certa forma notificar (O 1).

Eu uso muito o agente de saúde, que é o que está lá dentro da casa (E 2).

Como o agente de saúde tá 24 horas dentro do território, ele sabe tudo que está acontecendo e aí, caso aconteça, geralmente ele nos informa (E 5).

A importância do ACS no manejo dos casos de violência é inquestionável, uma vez que esse profissional constitui um elo entre a unidade de saúde e a comunidade, atuando diretamente com as famílias, além da possível formação de vínculo mais fortalecido com os usuários do serviço, o que possibilita uma melhor visualização da situação no ambiente domiciliar. Por outro lado, torna-se a categoria profissional mais exposta e mais temerosa em denunciar os casos de violência, por haver um possível comprometimento com a comunidade onde moram e trabalham (Gebara, Lourenço e Ronzani, 2013). 
Portanto, os profissionais de saúde devem buscar alternativas para preservar o ACS dessa tarefa, pois, por residirem no mesmo território em que exercem suas atividades profissionais, essa condição pode promover o desenvolvimento de privações e sofrimentos emocionais e consequências negativas para sua qualidade de vida e de trabalho (Menegussi, Ogata e Rosalini, 2014).

A denúncia da violência contra crianças e adolescentes é prevista pelo Ministério da Saúde, por meio da portaria MS/GM n. 1.968/2001, que discorre sobre a notificação, dos casos suspeitos ou confirmados atendidos nos serviços do Sistema Único de Saúde, às autoridades competentes (Brasil, 2012; Luna, Ferreira e Vieira, 2010).

A proteção de crianças e adolescentes também está contemplada no ECA, o qual afirma que os profissionais (médicos, professores e responsáveis por estabelecimentos de saúde e educação) têm o dever legal de notificar os casos suspeitos ou confirmados de violência aos conselhos tutelares, estando passíveis de penalidades aqueles profissionais que deixarem de comunicar às autoridades os casos de que tenham conhecimento (Brasil, 2008). Nesse intuito, a ficha de notificação/investigação individual de violência doméstica, sexual e/ou outras violências foi lançada pelo Ministério da Saúde, possibilitando a notificação da violência em suas diversas formas de manifestação (Brasil, 2012).

Ao serem questionados quanto à realização da notificação de casos de violência, alguns entrevistados afirmam notificar; outros, porém, demonstraram não terem conhecimento dessa ficha ou afirmaram ser necessário utilizá-la apenas diante da confirmação da violência, conforme expressam as seguintes falas:

Normalmente quando assim, quando a gente suspeita, uma suspeita que dê um sinal (...) que passe uma coisa que seja bem visível, porque a gente fica também naquela, como é que a gente vai notificar se a gente não tem certeza, né? (O 1).

Nunca peguei essa ficha, porque também nunca teve caso aqui. Eu nem sei como é não, essa ficha (O 4).

Dois profissionais referiram não ter contato com a ficha de notificação compulsória para os casos de violência e acidentes. Porém, ela foi encontrada em todas as unidades de saúde onde foram realizadas as entrevistas.

A notificação constitui um instrumento de defesa às crianças e adolescentes vítimas de violência intrafamiliar. Essa ferramenta, além de revelar a extensão da violência, permitindo o dimensionamento epidemiológico do problema, subsidia o desenvolvimento de políticas públicas voltadas para a prevenção de casos de violência e promoção do aperfeiçoamento das redes 
de proteção a esse grupo. Entretanto, estudos evidenciam que, apesar de a notificação ser considerada extremamente importante para visibilidade do problema e interrupção da violência, é baixo o seu índice de execução (Lima et al., 2011).

Logo, percebe-se o desconhecimento das condutas legais a serem realizadas diante desses casos e a carência de meios legais de proteção ao notificante, como fatores que influenciam negativamente na decisão do profissional, que acaba optando por não denunciar.

\section{Considerações finais}

As políticas públicas que estabelecem a participação dos serviços de saúde na identificação e enfrentamento da violência contra crianças e adolescentes não garantem que a equipe da ESF tenha competência para lidar com a situação.

O estudo evidenciou que a violência é mais percebida quando se torna explícita, principalmente a agressão física, que, por deixar marcas evidentes, é mais fácil de ser identificada. Porém, a violência psicológica, que não apresenta sinais tão claros e as vítimas têm resistência em relatar o ocorrido, dificulta a tomada de decisão do profissional de saúde e constitui uma barreira inicial no atendimento às vítimas. Por isso, ressalta-se a importância da abordagem dessa temática ainda na formação acadêmica, de modo a fortalecer o conhecimento sobre os aspectos que envolvem a violência contra crianças e adolescentes, a fim de sensibilizar os futuros profissionais para o manejo das situações vivenciadas.

Os resultados revelam que os profissionais mostram-se inseguros e despreparados para lidar com esse tipo de situação. Na maioria das vezes, o caso passa despercebido ou ignorado. Pelo fato de a ESF constituir espaço privilegiado para o reconhecimento dos casos de violência, com possibilidade de intervenção imediata, ressalta-se a importância da capacitação dos profissionais de saúde que atuam nesses serviços, com a proposta de integrar o atendimento em saúde, viabilizando a identificação precoce, a notificação dos casos e a efetivação do acompanhamento às vítimas e seus familiares.

O temor de ser identificado e sofrer represálias por parte dos agressores, muitas vezes pela carência de proteção ao profissional que denuncia, além da fragilidade da rede de cuidados, constitui barreiras para uma conduta eficaz pela equipe da ESF. Esse quadro expressa a necessidade de diálogo com os gestores, a fim de rever aspectos da legislação e organização dos serviços, de forma a resguardar os profissionais notificantes e fortalecer a rede de apoio, estabelecendo um fluxo de cuidados multidisciplinar e intersetorial integrados e potencialmente resolutivos. 
Acredita-se que a realização deste estudo amplia a percepção para a necessidade de ações que auxiliem no manejo da violência contra crianças e adolescentes por meio de políticas públicas de enfrentamento dessa situação e que os serviços de saúde se organizem a partir de uma perspectiva interdisciplinar para proteção aos profissionais de saúde, como também estabeleça uma linha de cuidado para a atenção integral à saúde de criança, adolescente e suas famílias em situação de violências, articulada com a rede de cuidado e de proteção social existente no território.

\section{Agradecimentos}

Aos profissionais que aceitaram participar deste estudo, por sua contribuição para a ampliar o conhecimento sobre a temática de violência intrafamiliar contra crianças e adolescentes.

\section{Colaboradores}

A autora Dayse Kalyne Gomes da Costa realizou a pesquisa de campo e participou de todas as etapas de produção do artigo; Lucas Pereira Reichert, Jael Rúbia Figueiredo de Sá França e Neusa Collet contribuíram na análise dos resultados, redação do texto e revisão final; Altamira Pereira da Silva Reichert participou da orientação da pesquisa e das demais etapas do artigo. 
Resumen Estudio cualitativo con profesionales de la Estrategia Salud de la Familia, a fin de investigar sus concepciones y prácticas acerca de la violencia intrafamiliar contra niños y adolescentes. La recolección de datos se realizó en el período de abril a julio de 2014, mediante entrevista semiestructurada, realizada en Unidades Integradas de Salud de la Familia en João Pessoa, Paraíba, Brasil. El análisis temático puso de manifiesto que los profesionales de la salud se muestran inseguros y no preparados para tratar con la violencia intrafamiliar contra niños y adolescentes, lo que origina dificultades para identificar los malos tratos, realizar la denuncia y dar seguimiento a las víctimas. Se destaca la importancia del apoyo de la gestión en salud para la protección de los profesionales que tratan con casos de violencia y su capacitación, a fin de permitir la identificación temprana, la notificación de los casos y el efectivo seguimiento de las víctimas y sus familiares.

Palabras clave violencia doméstica; salud del niño; adolescente; atención primaria de la salud; profesional de la salud.

\section{Notas}

1 Universidade Federal da Paraíba, João Pessoa, Paraíba, Brasil.

<daysekalyne@gmail.com>

Correspondência: Rua Doutor José Carlos Cavalcante, 118, Ernani Sátiro, CEP 58080-800,

João Pessoa, Paraíba, Brasil.

2 Faculdade de Medicina Nova Esperança, João Pessoa, Paraíba, Brasil.

$<$ lucasreichert@oi.com.br>

3 Universidade Federal da Paraíba, Centro de Ciências da Saúde, Programa de Pós-Graduação em Enfermagem, Departamento de Enfermagem em Saúde Pública e de Psiquiatria.

<jaelrubia@gmail.com>

4 Universidade Federal da Paraíba, Centro de Ciências da Saúde, Programa de Pós-Graduação em Enfermagem, Mestrado Profissional em Saúde da Família, João Pessoa, Paraíba, Brasil.

$<$ neucollet@gmail.com>

5 Universidade Federal da Paraíba, Centro de Ciências da Saúde, Programa de Pós-Graduação em Enfermagem, Mestrado Profissional em Saúde da Família, Departamento de Enfermagem.

<altareichert@gmail.com>

6 Este artigo trata-se de texto inédito e não há, por parte dos autores, conflitos de interesse com relação à pesquisa. 


\section{Referências}

ALGERI, Simone; SOUZA, Luccas M. Violence against children and adolescents: a challenge in everyday nursing staff. Revista Latino-Americana de Enfermagem, Ribeirão Preto, v. 14, n. 4, p. 625-631, jul./ago. 2006. Disponível em: <www.scielo.br/pdf/rlae/ v14n4/v14n4a23.pdf $>$. Acesso em: 7 jul. 2014.

ANGELO, Margareth et al. Vivências de enfermeiros no cuidado de crianças vítimas de violência intrafamiliar: uma análise fenomenológica. Texto \& Contexto Enfermagem, Florianópolis, v. 22, n. 3, p. 585-562, jul./set. 2013. Disponível em: <www.scielo.br/pdf/tce/v22n3/ v22n3a03.pdf>. Acesso em: 27 nov. 2014.

ARAGÃO, Ailton S. et al. Abordagem dos casos de violência à criança pela enfermagem na atenção básica. Revista Latino-Americana de Enfermagem, Ribeirão Preto, v. 21, p. 172-179, jan./fev. 2013. (Número especial). Disponível em: <www.scielo.br/scielo.php?script= sci_arttext\&pid=S0104-11692013000700022\& $\operatorname{lng}=\mathrm{en} \& \mathrm{nrm}=\mathrm{iso}>$. Acesso em: 7 jul 2014.

BARDIN, Laurence. Análise de conteúdo. São Paulo: Edições 70; 2011.

BRASIL. Ministério da Saúde. Estatuto da criança e do adolescente: Lei federal n. 8.069, de 13 de julho de 1990. 3. ed. Brasília: Editora do Ministério da Saúde, 2008. 96 p. (Série E. Legislação de Saúde). Disponível em: $<$ http://bvsms.saude.gov.br/bvs/publicacoes/ estatuto_crianca_adolescente_3ed.pdf $>$. Acesso em: 18 abr. 2013.

BRASIL. Ministério da Saúde. Secretaria de Atenção à Saúde. Departamento de Ações Programáticas Estratégicas. Linha de cuidado para a atenção integral à saúde de crianças, adolescentes e suas famílias em situação de violências: orientação para gestores e profissionais de saúde. Brasília: Ministério da Saúde, 2010. (Série F. Comunicação e Educação em Saúde), Disponível em: <http://bvsms.saude. gov.br/bvs/publicacoes/linha_cuidado_ criancas_familias_violencias.pdf $>$. Acesso em: 11 mar. 2013.
BRASIL. Ministério da Saúde. Secretaria de Atenção à Saúde. Departamento de Atenção Básica. Saúde da criança: crescimento e desenvolvimento. Brasília: Ministério da Saúde, 2012. 272 p. (Cadernos de Atenção Básica, n. 33).

BRASIL. Presidência da República. Casa Civil. Subchefia para Assuntos Jurídicos. Lei n. 13.010 , de 26 de junho de 2014. Altera a lei n. 8.069, de 13 de julho de 1990 (Estatuto da Criança e do Adolescente), para estabelecer o direito da criança e do adolescente de serem educados e cuidados sem o uso de castigos físicos ou de tratamento cruel ou degradante, e altera a lei n. 9.394, de 20 de dezembro de 1996. Diário Oficial da República Federativa do Brasil, Poder Executivo, Brasília, DF, 3 jul. 2014. Disponível em: <www. planalto.gov.br/ccivil_03/_Ato2011-2014/ 2014/Lei/L13010.htm>. Acesso em: 26 ago. 2014.

COCCO, Marta et al. Violência contra crianças e adolescentes: estratégias de cuidado adotadas por profissionais de saúde. Ciência, Cuidado e Saúde, Maringá, v. 9, n. 2, p. 292-300, abr./jun. 2010. Disponível em: $<$ http://periodicos.uem.br/ojs/index.php/ CiencCuidSaude/article/view/8061/6108>. Acesso em: 19 dez. 2013.

COCCO, Marta; SILVA, Ethel B.; JAHN, Alice C. Abordagem dos profissionais de saúde em instituições hospitalares a crianças e adolescentes vítimas de violência. Revista Eletrônica de Enfermagem, Goiânia, v. 12, n. 3, p. 491-497, 2010. Disponível em: <www. fen.ufg.br/revista/v12/n3/v12n3all.htm >. Acesso em: 16 abr. 2013.

CUEVAS, Carlos A. et al. Psychological distress as a risk factor for re-victimization in children. Child Abuse \& Neglect, Oxford, v. 34, n. 4, p. 235-243, Abr. 2010.

GEBARA, Carla F. P.; LOURENÇO, Lélio M.; RONZANI, Telmo M. A violência doméstica infantojuvenil na perspectiva dos agentes 
comunitários de saúde. Psicologia em Estudo, Maringá, v. 18, n. 3, p. 441-451, jul./set. 2013. Disponível em: <www.scielo.br/scielo. php? script $=$ sci_arttext \& pid $=$ S 1413 $73722013000300006 \& \operatorname{lng}=\mathrm{en} \& \mathrm{nrm}=\mathrm{iso}>$. Acesso em: 7 ago. 2014.

LIMA, Maria C. C. S. et al. Atuação profissional da atenção básica de saúde face à identificação e notificação da violência infantojuvenil. Revista Baiana de Saúde Pública, Salvador, v. 35, supl. 1, p. 118-137, jan./jun. 2011. Disponível em: <http://bases. bireme.br/cgi-bin/wxislind.exe/iah/online/ ?IsisScript $=\mathrm{iah} / \mathrm{iah} . \mathrm{xis} \&$ src $=$ google $\&$ base $=$ LILACS\&lang $=$ p \&next Action $=\operatorname{lnk} \&$ exprSearch $=602442$ \&indexSearch $=$ ID $>$. Acesso em: 19 dez. 2012.

LUNA, Geisy L. M.; FERREIRA, Renata C.; VIEIRA, Luiza J. E. S. Notificação de maus-tratos em crianças e adolescentes por profissionais da Equipe Saúde da Família. Ciência \& Saúde Coletiva, Rio de Janeiro, v. 15, n. 2, p. 481-491, mar. 2010. Disponível em: <www. scielo.br/scielo.php?script $=$ sci_arttext \& pid $=$ S1413-81232010000200025\&lng= en $\& n r m=i s o>$. Acesso em: 15 mar. 2013.

MENEGUSSI, Juliana M.; OGATA, Márcia N.; ROSALINI, Maria H. P. O agente comunitário de saúde como morador, trabalhador e usuário em São Carlos, São Paulo. Trabalho, Educação e Saúde, Rio de Janeiro, v. 12, n. 1, p. 87-106, jan./abr. 2014. Disponível em: <www. scielo.br/scielo.php?script=sci_arttext\&pid= S1981-77462014000100006\&lng=pt\&nrm= iso >. Acesso em: 4 Ago. 2014.

MOREIRA, Maria I. C.; SOUSA, Sônia M. G. Violência intrafamiliar contra crianças e adolescentes: do espaço privado à cena pública. Revista O Social em Questão, Rio de Janeiro, ano XV, n. 28, p. 13-26, 2012. Disponível em: <http://osocialemquestao.ser.puc-rio.br/ media/2artigo.pdf>. Acesso em: 27 Nov. 2014.

NUNES, Cristina B.; SARTI, Cynthia A.; OHARA, Conceição V. S. Profissionais de saúde e violência intrafamiliar contra a criança e adolescente. Acta Paulista de Enfermagem,
São Paulo, v. 22, p. 903-908, 2009. (Especial 70 Anos). Disponível em: <www.scielo.br/ pdf/ape/v22nspe/12.pdf $>$. Acesso em: 8 mar. 2013.

ROCHA, Pedro C. X.; MORAES, Claudia L. Violência familiar contra a criança e perspectivas de intervenção do Programa Saúde da Família: a experiência do PMF/Niterói (RJ, Brasil). Ciência \& Saúde Coletiva, Rio de Janeiro, v. 16, n. 7, p. 3.285-3.296, jul. 2011. Disponível em: <www.scielo.br/scielo.php?script= sci_arttext\&pid=S1413-81232011000800028\& lng $=$ en\&nrm=iso > . Acesso em: 13 mar. 2013.

SARAIVA, Renata J. et al. Qualificação do enfermeiro no cuidado a vítimas de violência doméstica infantil. Ciencia Enfermería, Concepción, v. 18, n.1, p. 17-27, abr. 2012. Disponível em: <www.scielo.cl/scielo. php? script $=$ sci_arttext \& pid $=$ S0 717 95532012000100003\&lng=es\&nrm=iso $>$. Acesso em: 13 mar. 2013.

SILVA, Lygia M. P.; FERRIANI, Maria G. C.; SILVA, Marta A. I. Atuação da enfermagem frente à violência sexual contra crianças e adolescentes. Revista Brasileira de Enfermagem, Brasília, v. 64, n. 5, p. 919-924, set./out. 2011. Disponível em: <www.scielo.br/scielo. php? script $=$ sci_arttext \& pid $=$ S0034$71672011000500018 \& \operatorname{lng}=$ en $\& n r m=$ iso $>$. Acesso em: 19 dez. 2012.

SILVA, Priscila A. et al. A notificação da violência intrafamiliar contra crianças e adolescentes na percepção dos profissionais de saúde. Ciência, Cuidado e Saúde, Maringá, v. 8, n. 1, p. 56-62, jan./mar. 2009. Disponível em: <http://periodicos.uem.br/ojs/index.php/ CiencCuidSaude/article/viewFile/7774/ 4409>. Acesso em: 19 dez. 2012.

SOUZA, Edinilsa R. et al. O tema violência intrafamiliar na concepção dos formadores dos profissionais de saúde. Ciência \& Saúde Coletiva, Rio de Janeiro, v. 14, n. 5, p. 1.709-1.719, Dec. 2009. Disponível em: <www.scielo.br/ scielo.php?script $=$ sci_arttext $\&$ pid $=$ S1413$81232009000500012 \& \operatorname{lng}=\mathrm{en} \& \mathrm{nrm}=\mathrm{iso}>$. Acesso em: 8 mar. 2013. 
TEIXEIRA, Clotilde et al. O vínculo entre usuários e equipes em duas Unidades de Saúde da Família em um município do Estado do Rio de Janeiro. Revista APS, Juiz de Fora, v. 16, n. 4, p. 444-454, Out./Dez. 2013. Disponível em: <http://aps.ufjf.emnuvens.com. br/aps/article/view/1725>. Acesso em: 7 ago. 2014.

THOMAZINE, Angélica M.; OLIVEIRA, Beatriz R. G; VIEIRA, Claudia S. Atenção a crianças e adolescentes vítimas de violência intrafamiliar por enfermeiros em serviços de pronto-atendimento. Revista Eletrônica de Enfermagem, Goiânia, v. 11, n. 4, p. 830-840, 2009. Disponível em: <www.fen.ufg.br/revista/v1l/ n4/v1ln4a08.htm>. Acesso em: 19 dez. 2012.
WAISELFISZ, Julio J. Mapa da violência: crianças e adolescentes do Brasil. Rio de Janeiro: Flasco Brasil, 2012. Disponível em: $<$ http://mapadaviolencia.org.br $>$. Acesso em: 19 dez. 2012.

Recebido em 16/06/2014

Aprovado em 04/12/2014 